\title{
PENGARUH HASIL ANALISIS FUNDAMENTAL TERHADAP RETURN SAHAM PT RAMAYANA LESTARI SENTOSA TBK
}

\author{
Herdiyana \\ Dosen Tetap Fakultas Ekonomi Universitas Pakuan \\ Lecturer of Economic Faculty at Pakuan University \\ Kartika \\ Mahasiswa Fakultas Ekonomi Universitas Pakuan \\ Student of Economic Faculty at Pakuan University
}

\begin{abstract}
ABSTRAK
Perusahaan dapat dikatakan memiliki fundamental yang baik jika perusahaan memiliki aset lancar yang tidak menggelembung dan penjualan biasa saja, total aset dan total modal lebih besar dari total hutang, dan nilai Earning Per Share memiliki pertumbuhan yang positif selama lima tahun terakhir. Semakin tinggi Earning Per Share maka semakin tinggi harga saham. Hal tersebut bertolak belakang dengan fakta yang ada pada PT Ramayana Lestari Sentosa, Tbk karena perusahaan tersebut memiliki pertumbuhan aset lancar yang meningkat disaat tingkat pertumbuhan penjualan menurun pada periode 2008-2009. Metode penelitian yang digunakan dalam penelitian ini adalah explanatory survey. Hasil penelitian menyatakan bahwa tidak didapatkan hasil pada Current Ratio dan Debt to Equity Ratio, karena pada variabel tersebut terjadi masalah multikolinearitas pada saat pengujian. Total Asset Turnover dan Net Profit Margin secara parsial berpengaruh terhadap harga saham. Total Asset Turnover secara parsial berpengaruh terhadap return saham, sedangkan Net Profit Margin secara parsial tidak berpengaruh terhadap return saham. Secara simultan Total Asset Turnover dan Net Profit Margin yang merupakan hasil analisis fundamental berpengaruh terhadap harga saham dan return saham.
\end{abstract}

Kata kunci: Current Ratio, Debt to Equity Ratio, Total Asset Turnover, Net Profit Margin, Harga Saham, Dividen Yield.

\begin{abstract}
The company can be knowledge have a good fundamentals if the company has current assets that are not bloated and mediocre sales, total assets and total capital is greater than the total debt, and the value of Earning Per Share has a positive growth over the last five years. The higher the earning per share, the higher the stock price. This contrasts with the fact that of the PT Ramayana Lestari Sentosa, Tbk because the company has current assets increased growth while the sales growth rate decreased in the period 2008-2009. The method used in this research is explanatory survey. The study states that the results obtained in the Current Ratio and Debt to Equity Ratio, due to the variable multikolinearitas problem occurs during testing. Total Asset Turnover and Net Profit Margin partially influence on stock prices. Total Asset Turnover partial effect on stock returns, while Net Profit Margin partially no effect on stock returns. Simultaneously Total Asset Turnover and Net Profit Margin is the result of fundamental analysis influence on stock prices and stock returns.
\end{abstract}

Keywords: Current Ratio, Debt to Equity Ratio, Total Asset Turnover, Net Profit Margin, Stock Price, Dividend Yield.

\section{Pendahuluan}

Pesatnya perkembangan

perekonomian yang terjadi di Indonesia dalam era globalisasi ini menjadikan pelaku bisnis khususnya para pemilik modal harus lebih teliti dalam mengambil suatu keputusan. Salah satu keputusan yang biasa digunakan oleh para pemilik modal adalah menanamkan modalnya atau ber-investasi, karena dengan perekonomian yang berkembang umumnya para pelaku bisnis berlombalomba untuk ikut mengembangkan kondisi ekonomi yang telah dimilikinya agar dapat lebih merasakan efek dari kondisi ekonomi yang telah berkembang 
dan tumbuh sangat pesat tersebut. Efek yang menjadi harapan para pemodal (investor) tidak lain adalah suatu keuntungan dari modal yang telah pemodal ikut sertakan dalam kegiatan ekonominya.

Tidak dapat dipungkiri bahwa return saham adalah suatu hal yang diharapkan dan menjadi motivasi investor dalam investasi. Keuntungan yang umum diharapkan oleh investor tidak lain yaitu keuntungan dari dividen saham (dividen yield), semakin tinggi harga pasar saham maka semakin kecil dividen yield, begitu juga semakin besar dividen perlembar saham yang dibagikan maka dividen yield semakin tinggi (Nor Hadi, 2013, 79). Selain dividen yield, keuntungan yang biasanya diharapkan oleh investor adalah keuntungan atas kenaikan harga pasar saham yang telah di beli dari suatu perusahaan (capital gains). Harga pasar saham merupakan cerminan dari kinerja suatu perusahaan, oleh karena itu banyak investor yang melakukan berbagai macam perhitungan atau analisis agar tidak mengalami suatu kerugian dan tentunya mendapatkan keuntungan (return).

Terdapat dua jenis analisis yang dapat digunakan dalam penilaian suatu saham untuk pengambilan keputusan investasi yaitu analisis fundamental dan analisis tekhnikal. Analisis fundamental merupakan pendekatan analisis harga saham yang menitik beratkan pada kinerja perusahaan dan ide dasar pendekatan ini adalah bahwa harga saham dipengaruhi oleh kinerja perusahaan. Sedangkan analisis tekhnikal hanya mempertimbangkan harga tanpa memperhatikan kinerja perusahaan (David Sukardi K. dan Kurniawan I., 2010, 1-2). Faktor fundamental yang digunakan dalam penelitian ini yaitu dari laporan keuangan itu sendiri dengan menggunakan analisis rasio keuangan antara lain Rasio Likuiditas, Rasio Solvabilitas, Rasio Aktivitas, dan Rasio Profitabilitas.

Berdasarkan teori yang diambil dari buku Desmond Wira (2011, 57-60) yang berkaitan dengan masalah fundamental, dimana keuangan perusahaan dikatakan baik jika aset lancar tidak menggelembung dan penjualan biasa saja, akan tetapi pada kenyataannya pada periode 2008-2009 aset lancar PT. Ramayana Lestari Sentosa, Tbk mengalami peningkatan, akan tetapi penjualan mengalami penurunan. Selain aset yang lancar tidak menggelembung dan penjualan biasa saja, keuangan perusahaan dapat dikatakan baik jika aset perusahaan lebih besar dari hutang, akan tetapi pada kenyataannya pada tahun 2009-2011, dilihat dari tingkat pertumbuhan aset PT. Ramayana Lestari Sentosa, Tbk selalu lebih kecil dari tingkat pertumbuhan hutang. Tidak hanya tingkat pertumbuhan aset yang selalu lebih kecil dari tingkat pertumbuhan hutang, tetapi pada tahun yang sama yaitu 2009-2011 tingkat pertumbuhan total modal juga selalu lebih kecil dari tingkat pertumbuhan hutang, hal ini tidak sesuai dengan teori yang menyatakan bahwa keuangan perusahaan dikatakan baik jika total modal lebih besar dari total hutang.

Berdasarkan teori yang diambil dari buku Desmond Wira yang berkaitan dengan Earning Per Share (EPS), dimana keuangan perusahaan dikatakan baik jika Earning Per Share memiliki pertumbuhan yang positif selama lima tahun terakhir, akan tetapi pada kenyataannya pada tahun 2008 sampai dengan tahun 2009 Earning Per Share PT. Ramayana Lestari Sentosa, Tbk. mengalami penurunan. Kemudian pada tahun 2009 sampai dengan tahun 2011 nilai Earning Per Share cenderung meningkat walaupun lebih kecil dibanding tahun 2007 sampai dengan 
tahun 2008. Menurut hasil penelitian Catur Wulandari (2005) yang dicatat oleh Yeye Susilowati (2011), nilai Earning Per Share sangat berpengaruh terhadap harga saham, semakin tinggi Earning Per Share maka harga saham akan semakin tinggi, akan tetapi pada kenyataannya pada tahun 2007-2008 dan 2010-2011 Earning Per Share meningkat, tapi harga saham menurun.

Tujuan dari penelitian ini adalah 1) Untuk melakukan analisis fundamental pada PT Ramayana Lestari Sentosa, Tbk; 2) Untuk menganalisis return saham pada PT Ramayana Lestari Sentosa, Tbk; dan 3) Untuk menganalisis pengaruh hasil analisis fundamental terhadap return saham PT Ramayana Lestari Sentosa Tbk.

\section{Metode Penelitian}

Metode penelitian yang digunakan dalam penelitian ini adalah explanatory survey yang merupakan metode yang bertujuan untuk menjelaskan hubungan perbedaan atau pengaruh suatu variabel dengan variabel yang lain (M. Burhan Bungin, 2010, 38).

\section{Hasil dan Pembahasan}

PT Ramayana Lestari Sentosa, Tbk dari tahun 1996 sampai dengan 2011 memiliki perkembangan yang relatif berfluktuasi. Nilai rata-rata Current Ratio PT. Ramayana Lestari Sentosa, Tbk yaitu sebesar 2,29. Nilai Current Ratio tertinggi berada pada tahun 2006 yaitu sebesar 3,18 keadaan ini disebabkan oleh lebih tingginya peningkatan nilai aktiva lancar yaitu sebesar 15,61\% dibandingkan peningkatan kewajiban lancar yang hanya $4,40 \%$. Nilai Current Ratio terendah berada pada tahun 1996 yaitu sebesar 1,46 keadaan ini disebabkan oleh jumlah aktiva lancar yang hanya memiliki sedikit selisih dengan kewajiban lancar.Likuiditas PT.
Ramayana Lestari Sentosa, Tbk dapat dikatakan relatif baik karena Current Ratio yang dimiliki dari tahun 1996 sampai 2011 melebihi angka 1 atau $100 \%$ dengan nilai rata-rata 2,29 yang artinya perusahaan mampu membayar hutang jangka pendeknya.

Debt to Equity Ratio PT. Ramayana Lestari Sentosa, Tbk dari tahun 1996 sampai dengan tahun 2011 memiliki perkembangan yang ralatif berfluktuasi. Nilai rata-rata Debt to Equity Ratio PT. Ramayana Lestari Sentosa, Tbk yaitu sebesar 0,52. Nilai tertinggi yang dimiliki yaitu sebesar 0,90 pada tahun 2001, keadaan ini disebabkan oleh peningkatan jumlah kewajiban yang lebih tinggi yaitu sebesar 33,01\% dibandingkan peningkatan jumlah ekuitas yaitu sebesar 22,44\%, keadaan ini menjelaskan bahwa pendanaan perusahaan lebih besar menggunakan jumlah kewajiban atau hutang dari pada modal sendiri. Nilai terendah terdapat pada tahun 2008 yaitu sebesar 0,29 keadaan ini disebabkan oleh penurunan jumlah kewajiban hingga $-11,39 \%$ sedangkan jumlah ekuitas meningkat sebesar 8,06\%. Keadaan ini menjelaskan bahwa pendanaan lebih di dominasi oleh jumlah ekuitas atau modal sendiri yang dimiliki oleh PT. Ramayana Lestari Sentosa, Tbk. Solvabilitas PT. Ramayana Lestari Sentosa, Tbk berdasarkan Debt to Equity Ratio, dapat dikatakan relatif baik karena memiliki nilai rata-rata dibawah 1 yaitu sebesar 0,52, kemudian jika dilihat dari besarnya nilai pada setiap tahun, dari 1996 sampai dengan tahun 2011 PT. Ramayana Lestari Sentosa, Tbk memiliki nilai Debt to Equity Ratio dibawah 1 atau $100 \%$ yang menunjukkan pendanaan perusahaan lebih besar menggunakan modal sendiri, dan mampu membayar hutang jangka panjangnya

$$
\text { Total Asset Turnover PT. }
$$

Ramayana Lestari Sentosa, Tbk dari 
tahun 1996 sampai dengan tahun 2011 relatif berfluktuasi. Nilai rata-rata Total Asset Turnover PT. Ramayana Lestari Sentosa, Tbk yaitu 1,48. Nilai tertinggi Total Asset Turnover PT. Ramayana Lestari Sentosa, Tbk terdapat pada tahun 2005 dan 2008 dengan nilai yang sama yaitu 1,84 keadaan tersebut disebabkan oleh peningkatan jumlah penjualan yang lebih tinggi dibandingkan peningkatan jumlah aktiva. Pada tahun 2005 peningkatan jumlah penjualan sebesar $13,17 \%$ akan tetapi jumlah aktiva mengalami penurunan yaitu sebesar $8,62 \%$, kemudian peningkatan jumlah penjualan di tahun 2008 yaitu sebesar $12,95 \%$ sedangkan peningkatan jumlah aktiva hanya sebesar $2,97 \%$. Keadaan tersebut menunjukan perusahaan relatif efektif dalam menggunakan jumlah aktiva untuk menghasilkan penjualan. Nilai terendah adalah sebesar 1,05 yang terdapat pada tahun 1996, keadaan ini disebabkan oleh selisih jumlah penjualan dan jumlah aktiva hanya sedikit. Aktivitas PT. Ramayana Lestari Sentosa, Tbk memiliki keadaan yang relatif baik jika dilihat dari nilai Total Asset Turnover, karena dari periode tahun yang diamati yaitu dari tahun 1996 sampai dengan tahun 2011 Total Asset Turnover PT. Ramayana Lestari Sentosa, Tbk mengalami 11 kali peningkatan.

Net Profit Margin, PT. Ramayana Lestari Sentosa, Tbk dari tahun pengamatan yaitu tahun 1996 sampai dengan 2011, Net Profit Margin PT. Ramayana Lestari Sentosa, Tbk dari tahun 1999 sampai dengan 2011 cenderung mengalami penurunan. Nilai rata- rata Net Profit Margin yang dimiliki oleh PT. Ramayana Lestari Sentosa, Tbk yaitu sebesar 0,08. Tahun 1999 merupakan tahun yang memiliki nilai Net Profit Margin tertinggi yaitu sebesar 0,13 keadaan ini disebabkan karena peningkatan laba bersih yang lebih tinggi dibandingkan peningkatan total penjualan. Peningkatan laba bersih sebesar $121,27 \%, \quad$ sedangkan peningkatan total penjualan hanya sebesar 27,49\%. Nilai Net Profit Margin terendah terdapat pada tahun 2009 sampai dengan tahun 2011 dengan nilai yang sama yaitu sebesar 0,06 keadaan ini disebabkan oleh peningkatan total penjualan yang lebih tinggi dibandingkan dengan peningkatan laba bersih. Profitabilitas PT. Ramayana Lestari Sentosa, Tbk dilihat dari nilai Net Profit Margin memiliki kondisi yang relatif kurang baik karena dari tahun 1999 sampai dengan tahun 2011 lebih banyak mengalami penurunan dari pada peningkatan. Keadaan tersebut menunjukan manajemen perusahaan relatif tidak efisien dalam menghasilkan keuntungan.

Harga saham dan dividen yield yang relatif berfluktuasi dari tahun 1996 sampai dengan 2011. Nilai rata-rata dari harga saham yaitu sebesar Rp. 2.431,-. Harga saham tertinggi terdapat pada tahun 1999 yaitu sebesar Rp. 5.250,keadaan ini disebabkan peningkatan kinerja perusahaan yang dilihat dari peningkatan laba bersih sebesar $121,27 \%$, peningkatan jumlah penjualan sebesar 27,49\%, peningkatan jumlah aset dan peningkatan jumlah ekuitas yang memiliki nilai yang sama yaitu sebesar $34,20 \%$, dan kecilnya peningkatan inflasi yaitu hanya sebesar $2,01 \%$, sehingga investor tertarik untuk melakukan investasi pada PT. Ramayana Lestari Sentosa, Tbk. Harga saham terendah terdapat pada tahun 2008 yaitu sebesar Rp. 500,-. keadaan ini disebabkan oleh peningkatan suku bunga sebesar $9,25 \%$, yang menjadikan investor menarik investasinya pada saham dan memindahkannya pada investasi berupa tabungan atau deposito.

Nilai rata-rata dari dividen yield yang dimiliki oleh PT. Ramayana Lestari sentosa, Tbk sebesar 3,02\%. Nilai 
tertinggi terdapat pada tahun 2008 dengan nilai dividen yield sebesar $6,20 \%$ keadaan ini disebabkan oleh kecilnya harga saham pada tahun tersebut. Tahun 1997 merupakan tahun yang memiliki nilai dividen yield terendah sebesar $0,97 \%$ keadaan ini disebabkan oleh harga saham yang tinggi.

\section{Kesimpulan}

1. Fundamental PT. Ramayana Lestari Sentosa, Tbk dilihat dari Current Ratio, Debt to Equity Ratio, dan Total Asset Turnover, dapat dikatakan relatif baik karena Current Ratio memiliki rata-rata nilai diatas 1, Debt to Equity Ratio memiliki nilai rata-rata dibawah 1 , dan Total Asset Turnover memiliki lebih banyak peningkatan dibandingkan penuruan akan tetapi Net Profit Margin dapat dikatakan relatif kurang baik karena perkembangannya cenderung mengalami penurunan.

2. Return saham PT. Ramayana Lestari Sentosa, Tbk dari 16 tahun pengamatan secara umum perkembangannya mengalami fluktuasi, akan tetapi jika dilihat pada akhir tahun yaitu tahun 2011 harga saham mengalami penurunan hingga $-15,29 \%$ dari keadaan tersebut menunjukan bahwa investor mengalami kerugian (capital loss), meskipun dividen yield mengalami peningkatan, akan tetapi peningkatan tersebut tidak lebih tinggi dari peningkatan pada tahun 2008.

3. Berdasarkan hasil olahan data dengan menggunakan program SPSS berikut simpulan yang dapat dikemukakan penulis, yaitu: Total Asset Turnover dan Net Profit Margin secara parsial berpengaruh terhadap harga saham. Total Asset

$\begin{aligned} & \text { Turnover secara } \\ & \text { berpengaruh terhadap }\end{aligned} \begin{array}{r}\text { parsial } \\ \text { return }\end{array}$
saham, sedangkan Net Profit
Margin secara parsial $\begin{array}{r}\text { tidak } \\ \text { berpengaruh terhadap return }\end{array}$
saham. Secara simultan Total Asset
Turnover dan Net Profit Margin
yang merupakan hasil analisis
fundamental berpengaruh terhadap
harga saham dan return saham.

\section{Daftar Pustaka}

Darsono P. 2006. Manajemen Keuangan, Diadit Media, Jakarta.

David Sukardi K. dan Kurniawan I. 2010. Manajemen Investasi (Pendekatan Tekhnikal dan Fundamental Untuk analisis saham). Andi, Yogyakarta.

Desmond Wira. 2011. Analisis Fundamental. Exceed.

Hardono Mardiyanto. 2009. Intisari Manajemen Keuangan. PT. Grasindo, Jakarta

Kasmir. 2010. Pengantar Manajemen Keuangan. Edisi Pertama Kencana Preneda Media Group, Jakarta.

Keown J Arthur., John D Martin., J William P., dan Daud F Scott. 2011. Manajemen Keuangan (Prinsip dan Penerapan). Edisi 10. Alih Bahasa: Marcus P Widodo. Indeks.

M. Burhan Bungin. 2010. Metodologi Penelitian Kuantitatif (Komunikasi, Ekonomi, dan Kebijakan Publik Serta Ilmu-ilmu Sosial Lainnya. Kencana, Jakarta

Mamduh M. Hanafi dan Abdul Halim. 2000. Analisis Laporan Keuangan. Edisi Kedua. UPP AMPYKPN. Yogyakarta.

Nor Hadi. 2013. Pasar Modal (Acuan Teoritis dan Praktis di Instrumen Keuangan Pasar Modal). Graha Ilmu, Yogyakarta. 
Scott, Besley and Eugene F. Brigham. 2008. Principles of Finance, Cengage Learning, South-Western. Subalno. 2009. Analisis Pengaruh Faktor Fundamental dan Kondisi Ekonomi Terhadap Return. Tesis Program Studi Magister Manajemen Program Pasca Sarjana Universitas Diponegoro Semarang. (Diakses 27 juli 2012).

Toto Prihadi. 2011. Praktis Memahami Laporan Keuangan Sesuai IFRS \& PSAK, PPM- Manajemen. Jogjakarta. 